\title{
CHAOS IN BRAIN?
}


This page is intentionally left blank 


\title{
WORKSHOP ON \\ CHAOS IN BRAIN?
}

\author{
NIC, Forschungszentrum Jülich and \\ Dept. of Epileptology, University of Bonn, Germany \\ March 10-12,1999
}

\author{
edited by \\ K. Lehnertz \\ Dept. of Epileptology \\ University of Bonn, Germany \\ J. Arnhold \\ NIC, Forschungszentrum Jülich, \\ Germany \\ P. Grassberger \\ NIC, Forschungszentrum Jülich, \\ Germany \\ C.E. Elger \\ Dept. of Epileptology, \\ University of Bonn, Germany
}




\title{
Published by
}

World Scientific Publishing Co. Pte. Ltd.

P O Box 128, Farrer Road, Singapore 912805

USA office: Suite 1B, 1060 Main Street, River Edge, NJ 07661

UK office: 57 Shelton Street, Covent Garden, London WC2H 9HE

\section{British Library Cataloguing-in-Publication Data}

A catalogue record for this book is available from the British Library.

\begin{abstract}
CHAOS IN BRAIN?
Proceedings of the 1999 Workshop

Copyright $\odot 2000$ by World Scientific Publishing Co. Pte. Ltd.

All rights reserved. This book, or parts thereof, may not be reproduced in any form or by any means, electronic or mechanical, including photocopying, recording or any information storage and retrieval system now known or to be invented, without written permission from the Publisher.
\end{abstract}

For photocopying of material in this volume, please pay a copying fee through the Copyright Clearance Center, Inc., 222 Rosewood Drive, Danvers, MA 01923, USA. In this case permission to photocopy is not required from the publisher.

ISBN 981-02-4222-0

Printed in Singapore by Uto-Print 


\section{PREFACE}

During the last years, chaos theory has been repeatedly applied to a variety of brain electromagnetic signals. Especially in pathological states - like epilepsy nonlinear time series analysis (NTSA) of the electroencephalogram provides valuable insights and promise important for clinical use. However, despite wide interest from several neuroscience disciplines, many potential users of NTSA are not sufficiently familiar with modern methods. On the other hand, researchers developing new concepts and algorithms for time series analysis often lack the necessary neuroscientific and medical knowledge. Thus, it seemed timely to bring together different physical, mathematical, neuroscientific, and clinical expertise to guarantee successful applications of NTSA methods to brain dynamics, thereby stimulating the exchange of ideas and techniques. We believe that the interdisciplinary workshop on "Chaos in Brain?" held in Bonn from 10 - 12 March 1999, succeeded in doing so. One hundred and thirty-five researchers from ten different countries participated in the workshop; talks and poster contributions collected in the present proceedings give ample evidence for its success.

The workshop was organized by the John von Neumann-Institute for Computing (NIC) at the Forschungszentrum Jülich and the Department of Epileptology of the Bonn University Medical Center. The NIC was founded in July 1998 by the Forschungszentrum Jülich and the Stiftung Deutsches Elektronen-Synchrotron (DESY) to advance supercomputer-oriented scientific research. The NIC is the successor of the Höchstleistungsrechenzentrum (HLRZ) and continues the successful work in the area of supercomputing and its applications. This includes allocation of supercomputing resources for research projects in academia, research institutes, and industry as well as engagement of supercomputer-oriented research in selected areas of physics, chemistry, and other disciplines. The Department of Epileptology of the University of Bonn hosts the only Chair for Epileptology in Germany. In cooperation with the Department of Neurosurgery, it is one of the leading epilepsy centers in the world. One important research project - funded by the Deutsche Forschungsgemeinschaft - focuses on nonlinear EEG analysis to understand brain functions and epileptogenic processes as well as anticipation and prevention of epileptic seizures.

We are very grateful to the financial support from the German Section of the International League against Epilepsy, the German Society for Clinical Neurophysiology, and the Forschungszentrum Jülich which made the workshop possible. But even more important for its frictionless organization was the efficiency and cheerfulness of the conference secretaries H. Frank and A. Deußen, and the help of B. Krahl-Urban from the public relations office of the Forschungszentrum.

Bonn and Jülich, August 1999

Klaus Lehnertz

Jochen Arnhold

Peter Grassberger

Christian E. Elger 
This page is intentionally left blank 


\section{CONTENTS}

PREFACE

\section{LECTURES}

Cortical dynamics - experiments and models

$S$. Rotter and A. Aertsen

Is nonlinearity evident in time series of brain electrical activity?

T. Schreiber

Finding and characterizing unstable fixed points by controlling system dynamics

D.T. Kaplan

Detection of phase locking from noisy data: application to magnetoencephalography

M. Rosenblum, P. Tass, J. Kurths, J. Volkmann, A. Schnitzler and H.-J. Freund

Dynamical analysis in clinical practice P.E. Rapp and T.I. Schmah

Rhythms of the brain: between randomness and determinism

F.H. Lopes da Silva, J.P.M. Pijn, J.A. Gorter, E. van Vliet, E.W. Daalman and $W$. Blanes

Pre-ictal changes of the EEG dynamics in epileptic patients: clinical and neurobiological implications

M. Baulac, M. Le van Quyen, J. Martinerie, S. Clemenceau, C. Adam and F.J. Varela

Spatio-temporal dynamics of epileptogenic networks

M. Le van Quyen, J. Martinerie and F.J. Varela

Pre-ictal changes and EEG analyses within the framework of Lyapunov theory

H.R. Moser, P.F. Meier, H.G. Wieser and B. Weber

Epilepsy - when chaos fails

J.C. Sackellares , L.D. Iasemidis, D.-S. Shiau, R.L. Gilmore and S.N. Roper

Possible clinical and research applications of nonlinear EEG analysis in humans

K. Lehnertz, R.G. Andrzejak, J. Arnhold, G. Widman, W. Burr, P. David and C.E. Elger

Dynamics of EEG signals during petit-mal epileptic seizures

R. Friedrich 
Detection of epileptic dynamics in neuromagnetic signals: spectral analyses versus characteristics of correlation function

E. Bohl, R. Kenzler, T. Elbert, B. Rockstroh and C.E. Elger

Nonlinear methods for evoked potential analysis and modeling

B.H. Jansen

From slow potentials to chaos: processing in the brain and controlling the brain

H. Preißl and W. Lutzenberger

\section{POSTERS}

Detection of deterministic dynamics in short discrete time series

A. Celletti, C. Froeschlé, I.V. Tetko and A.E.P. Villa

Characterization of linear and nonlinear structure in high-dimensional, spatially extended systems: the algorithm of multichannel nonlinear cross prediction

C.J. Stam and W.S. Pritchard

Surrogate data for non-stationary signals

A. Schmitz and T. Schreiber

Analysis of fluctuating data sets of diffusion processes

S. Siegert, R. Friedrich and P. Hänggi

Complications in applying the method of surrogate data to EEG

D. Kugiumtzis

Spontaneous synchronisation in a discrete neural network model

D. Volk

Patterns of complexity and coherent oscillations in a thalamo-cortical network model

J. Schwarz, A. Stevens, K. Bräuer and M. Bartels

Non-linear coupling of local field potentials across cortical sites in parvalbumin-deficient mice

A.E.P. Villa, P. Dutoit, I.V. Tetko, W. Hunziker, M. Celio and B. Schwaller

Analytical proof of chaos in single neurons and consequences

L. Andrey

EEG-detected episodes of low-dimensional self-organized cortical activity and the problem of chaos in the brain

R. Cerf, E.H. El Ouasdad and M. El Amri

Correlation dimension as a method to investigate human REM-sleep

G. Fritzer and T. Maß 
The application of a non-linear analysis technique to the monitoring of anesthetic effects in the rat

P.L.C. van den Broek, J. van Egmond, C.M. van Rijn, R. Dirksen,

A.M.L. Coenen and L.H.D.J. Booij

Detection of determinism in EEG time series from human sleep by an interspike interval approach

A. Galka

Detecting spatio-temporal information flow in the cortex by mutual information analysis of MEG data

L.-H. Hiss and B. Pompe

Evidence of inverse covariation between alpha power and correlation dimension in human brain dynamics

W.S. Tirsch, M. Keidel, S. Perz, H. Scherb and G. Sommer

Correlation sums from EEG time series: a measure to quantify depth of anesthesia

G. Widman, B. Rehberg, A. Hoeft, K. Lehnertz and C.E. Elger

Detection of phase synchronization in human MEG data

P. Tass, J. Gross, M.G. Rosenblum, A. Schnitzler, J. Volkmann,

$J$. Kurths and H.-J. Freund

MEG-recordings of syllables perception: perturbations from a stable state in the auditory cortex

K. Mathiak, I. Hertrich, W. Lutzenberger and H. Ackermann

Measuring changes in cognitive event related potentials

R.A. Pittenger, A.M. Albano, R.C. Josiassen and P.E. Rapp

Fast subdural signals in humans show task- and event-related changes of conventional and novel coupling measures during cognitive processes

A. Bruns, R. Eckhorn, H. Jokeit and A. Ebner

Brain activity detected by complexity measurements: a methodological approach

R. Mammoliti, M.F. Santarelli, A. Benassi and L. Landini

Phase-locking of event-related alpha oscillations

R. Quian Quiroga, E. Başar and M. Schürmann

Nonlinear filtering in wavelet domain: application to single trial analysis of limbic P300 potentials

A. Effern, K. Lehnertz, T. Grunwald, P. David and C.E. Elger

Influence of the power-spectrum of the pre-stimulus EEG on the consecutive auditory evoked potential in rats

M.L.A. Jongsma, C.M. van Rijn, R. Quian Quiroga, W.J. van Schaijk,

R. Dirksen and A.M.L. Coenen 
Efficient ARMA modeling of ECOG data of epileptic patients during pre-ictal, inter-ictal and ictal states

D.C. Boronowski and P.D. Spanos

Characterization of nonlinear dynamics in the scalp EEG of epileptic seizures

U. Möller, K. Schmidt, H. Witte and M. Feucht

The use of principal component analysis in the analysis of depth recordings during epileptic seizures

S.V. Notley, S.J. Elliott, L.E. Sundstrom, W.P. Gray, D. Lurton and $A$. Rougier

Detecting interdependences in intracranial EEG recordings of epilepsy patients

J. Arnhold, P. Grassberger, K. Lehnertz and C.E. Elger

Linear and nonlinear analysis of EEG for the prediction of epileptic seizures

D. Kugiumtzis and P.G. Larsson

Sensitive measures of condition change in EEG data

L.M. Hively, P.C. Gailey and V.A. Protopopescu

Bursting discharges in a mathematical model of the neocortex C. Hauptmann and F. Giannakopoulos

Nonlinear deterministic dynamics in seizure free EEG epochs as an indicator of the epileptogenic process. A comparison of three surrogate methods

R.G. Andrzejak, G. Widman, K. Lehnertz, P. David and C.E. Elger

EEG dimensional complexity mapping in stroke

M. Molnár, Z. Nagy and J. Kenéz

Nonlinear dynamic in the EEG of schizophrenic patients and its variation with mental task

M. Dressel, B. Ambühl-Braun, R. Dünki, P.F. Meier and T. Elbert

Nonlinear analysis of EEG slow-wave activity during sleep and sleep regulation modeling: a study in narcoleptic patients under bed rest conditions

R. Ferri, S. Pettinato, F. Ferrillo, L. Nobili and M. Billiard

The correlation dimension of absence-like phenomena in the EEGs of rats

C.M. van Rijn, P.L.C. van den Broek, R. Dirksen, J. van Egmond and A.M.L. Coenen

\section{LIST OF PARTICIPANTS}

